\title{
Study of angle of anterior chamber in patients with Type 2 Diabetes Mellitus
}

\author{
Khanna N. S. ${ }^{1}$, Anitha J. ${ }^{2}$ \\ ${ }^{1}$ Dr. N. Sindhu Khanna, Senior Resident, ${ }^{2}$ Dr. Anitha J., Assistant Professor, both authors are affiliated with Department \\ of Ophthalmology, Sapthagiri Institute of Medical Sciences and Research Center, Bangalore, Karnataka, India.
}

Corresponding Author: Dr. Anitha J, Assistant Professor, Department of Ophthalmology, Sapthagiri Institute of Medical Sciences and Research Center, Bangalore, Karnataka, India. E-mail: dranithasada@gmail.com

\begin{abstract}
Introduction: Open angle Glaucoma is one of the causes of blindness in diabetic patients. Whether diabetes is a risk factor for angle closure glaucoma also is less thoroughly studied. Objectives: To assess the angle of anterior chamber in patients with type 2 diabetes mellitus. Materials and Method: 125 patients ( 250 eyes) who met the inclusion criteria were taken up for the study. Patients of both sexes and more than 40 years of age with Type 2 Diabetes Mellitus who do not come under the exclusion criteria were included. Results: In subjects with duration of diabetes $<5$ years, Grade 4 angle was found in $47.41 \%$ of eyes which was comparatively more than the other grades. When the duration of Diabetes was $5-10$ years, $40 \%$ of the eyes had Grade 4 angle and $37.27 \%$ had Grade 3 angle. In subjects with $>10$ years duration of diabetes, 33.33\% had Grade 3 angle. Grade 2 and Grade 4 angles were of equal distribution with $29.16 \%$ and Grade 1 was found to be less. The association of Grade 1 and Grade 3 angle with severe non-proliferative diabetic retinopathy was found to be statistically significant. Whereas, in patients with mild diabetic retinopathy and in moderate nonproliferative diabetic retinopathy Grade 4 angle is statistically significant. Conclusion: This study thus concludes the grade of angle of the anterior chamber decreases as the diabetic retinopathy advances.
\end{abstract}

Key words: Angle closure glaucoma, Diabetes, Retinopathy

\section{Introduction}

Glaucoma is one of the causes of blindness and its risk increases in diabetics. Most previous studies were conducted on Caucasians and have found the association between diabetes and open angle glaucoma $[1,2,3]$. Whether diabetes is a risk factor for angle closure glaucoma also is less clear and less thoroughly studied. There is some correlation between the width of angle of anterior chamber and diabetes mellitus which has been recognized in recent times. Any occludable angle can potentially lead to acute angle closure [4]. This study is done to prove the existing correlation of anterior chamber angle width with diabetes mellitus, thus helping in an early diagnosis of angle closure and preventing its complications.

\section{Aims and objectives}

To assess the angle of anterior chamber in patients with type 2 diabetes mellitus.

Manuscript received: $4^{\text {th }}$ March 2019

Reviewed: $14^{\text {th }}$ March 2019

Author Corrected: $20^{\text {th }}$ March 2019

Accepted for Publication: $26^{\text {th }}$ March 2019

\section{Materials and Methods}

A hospital based cross sectional clinical study of patients with diabetes mellitus was conducted in a Tertiary care centre. Informed and written consent was taken from the patients. 125 patients (250eyes) who met the inclusion criteria were taken up for the study.

Patients of both sexes and more than 40 years of age with Type 2 Diabetes Mellitus who do not come under the exclusion criteria were included. Patients with history of ocular inflammations, ocular surgeries, blunt or penetrating ocular trauma were excluded. A detailed proforma is devised for the collection of data.

After taking an informed consent, all subjects underwent the following work up:

Detailed history of patients regarding name, age, sex, occupation, address, drug history, presenting symptoms, duration, associated conditions and past history was recorded. Duration of diabetes and type of treatment was enquired. 
A complete ophthalmologic examination was done which includes best corrected visual acuity, intra-ocular pressure measurement, gonioscopy to view the angle of anterior chamber, detailed anterior segment examination and dilated fundus examination.

Perimetry was planned when the anterior chamber angle had Shaffer Grading 1 (or $<1$ ) or the optic disc changes suggestive of glaucoma was present. Dilated fundus examination was done to evaluate the optic disc and to grade the diabetic retinopathy changes according to ETDRS guidelines. Analysis of variance (ANOVA) was used for comparison between the groups for continuous variables.

Post- hoc test (Dunnett's test) was used for comparing the different groups with each other, with a confidence interval of $95 \%$. A p-value of less than 0.05 was considered statistically significant.

\section{Results}

A total of 125 patients (250 eyes) were enrolled in this study. The age group ranged from 40 to 80 years with a mean of $57.14 \pm 9.27$, out of which 64 were males and 61 were females. Among the 250 eyes, 5 eyes had Shaffer Grade 1 angle of anterior chamber which accounts to $2 \% .45$ eyes had Grade 2 angle accounting for $18 \%$. Grade 3 angle was found in 93 eyes implying $37.20 \%$. 107 eyes had grade 4 angle which accounts for $42.80 \%$.

Duration of diabetes has been classified into 3 categories as $<5$ years, 5-10 years and $>10$ years (Table 1 ) In subjects with duration of diabetes $<5$ years, Grade 4 angle was found in $47.41 \%$ of eyes which was comparatively more than the other grades (Table 2).

Table-1: Duration of Diabetes.

\begin{tabular}{|c|c|c|}
\hline Duration of diabetes & No. of patients & Percentage of patients \\
\hline Less than 5 years & 58 & $46.40 \%$ \\
\hline 5-10 years & 55 & $44 \%$ \\
\hline More than 10 years & 12 & $9.60 \%$ \\
\hline
\end{tabular}

Table-2: Distribution of Grades of angle structures in eyes with $<5$ years of duration of Diabetes Mellitus

\begin{tabular}{|c|c|}
\hline Grading of anterior chamber angle & Percentage \\
\hline Grade 1 & $1.72 \%$ \\
\hline Grade 2 & $12.06 \%$ \\
\hline Grade 3 & $37.93 \%$ \\
\hline Grade 4 & $47.41 \%$ \\
\hline
\end{tabular}

Table-3:Distribution of grades of angle structures in eyes with Diabetes Mellitus of 5-10 years of duration.

\begin{tabular}{|c|c|}
\hline Grading of anterior chamber angle & Percentage \\
\hline Grade 1 & $0.90 \%$ \\
\hline Grade 2 & $21.81 \%$ \\
\hline Grade 3 & $37.27 \%$ \\
\hline Grade 4 & $40 \%$ \\
\hline
\end{tabular}

When the duration of Diabetes was 5-10 years, $40 \%$ of the eyes had Grade 4 angle and $37.27 \%$ had Grade 3 angle(Table 3 )

Table-4: Distribution of Grades of angle structures in eyes with Diabetes Mellitus $>10$ years of duration

\begin{tabular}{|c|c|}
\hline Grading of anterior chamber angle & Percentage \\
\hline Grade 1 & $8.33 \%$ \\
\hline Grade 2 & $29.16 \%$ \\
\hline Grade 3 & $33.33 \%$ \\
\hline Grade 4 & $29.16 \%$ \\
\hline
\end{tabular}


In subjects with $>10$ years duration of diabetes, $33.33 \%$ had Grade 3 angle. Grade 2 and Grade 4 angles were of equal distribution with $29.16 \%$ and Grade 1 was found to be less. However when compared with the other groups Grade 1 was found to be statically significant ( $\mathrm{p}=0.045$ ) in patients with more than 10 years duration of diabetes mellitus (Table 4)

Table-5: Angle of anterior chamber with different grades of retinopathy

\begin{tabular}{|c|c|c|}
\hline Angles of anterior chamber & Retinopathy grading & P value \\
\hline \multirow{3}{*}{1} & Mild NPDR & 0.080 \\
\cline { 2 - 3 } & Moderate NPDR & 0.684 \\
\cline { 2 - 3 } & Severe NPDR & 0.000 \\
\hline \multirow{4}{*}{2} & Mild NPDR & 0.080 \\
\cline { 2 - 3 } & Moderate NPDR & 0.088 \\
\cline { 2 - 3 } & Severe NPDR & 0.039 \\
\hline \multirow{3}{*}{3} & Mild NPDR & 0.684 \\
\cline { 2 - 3 } & Moderate NPDR & 0.088 \\
\cline { 2 - 3 } & Severe NPDR & 0.000 \\
\hline \multirow{3}{*}{4} & Mild NPDR & 0.000 \\
\cline { 2 - 3 } & Moderate NPDR & 0.039 \\
\cline { 2 - 3 } & Severe NPDR & 0.000 \\
\hline
\end{tabular}

On comparing the width of angle of anterior chamber with severity of diabetic retinopathy, the following were noted.

The association of Grade 1 and Grade 3 angle with severe non-proliferative diabetic retinopathy was found to be statistically significant with a $\mathrm{p}$ value of 0.000 . Whereas, in patients with mild diabetic retinopathy and in moderate nonproliferative diabetic retinopathy Grade 4 angle is statistically significant (value of 0.000 ) (Table 5).

\section{Discussion}

Our study showed that the patients with type II diabetes mellitus had shallow anterior chamber in relation to the duration of the disease and severity of diabetic retinopathy. The relation was statistically significant with $\mathrm{p}$ value less than 0.05 .

Increasing lens thickness and decreasing anterior chamber depth with increasing duration of diabetes have been confirmed in a population based twin study and it was also found that anterior chamber depth was negatively correlated with duration of diabetes [5]. There have been no Indian studies done on the impact of angle of anterior chamber with respect to duration of diabetes. Tai MC, Lin SY et al proved that acute hyperglycemic status did not cause any significant change in anterior chamber depth, lens thickness [6].

Studies have found that diabetic patients have a shallower anterior chamber, thicker central cornea and lens. Tanjong Pagar Survey conducted by Seang Mei Saw and associates stated that in Singapore Chinese population with diabetes had shallower anterior chambers and thicker lens than those without diabetes [2]. In a study which involved 150 canine eyes, the anterior chamber depth was significantly reduced in eyes with diabetic cataracts compared with eyes with non-cataractous lens [7].
There is some correlation between the width of angle of anterior chamber and diabetes mellitus which has been recognized in recent times. Any occludable angle can potentially lead to acute angle closure [2]. Devereux and Foster conducted a cross- sectional study on 1000 Mongolian patients and concluded that the measurement of axial anterior chamber depth detects occludable angles in this Asian population and therefore they have a major role in screening for primary angle-closure glaucoma [8].

A two phase, cross sectional, community based study was conducted by Foster, Devereux et alon rural and urban areas of Mongolia where 1717 diabetic subjects were examined. Occludable angles were identified in 140 subjects, 28 of these had PACG.15\% were under grade 1 with a sensitivity and specificity of $84 \%$ and $86 \%$ respectively for the detection of occludable angles, thus proving the significance of occludable angle in diabetics [9].

According to Browning and Rotberg as the diabetic retinopathy severity progresses, the anterior chamber depth becomes shallow. It has been proved that certain treatment for diabetic retinopathy such as scleral buckling can lead to forward rotation of ciliary body and secondary narrowing of anterior chamber angle. 
Silicone oil or pneumatic retinopexy in which the gas is used, can also push the iris forward and obstruct the aqueous outflow. In our study we found out that Grade 1 angle was statistically significant in Severe NPDR group when compared to other groups. Whereas, Grade 4 angle was statistically significant in mild retinopathy group. This suggests that gonioscopy can be used as a screening tool in all patients with a longer duration of diabetes mellitus to rule out angle closure, thus preventing its complication further.

\section{Summary \& Conclusion}

Diabetes mellitus is a major health problem throughout the world and there has been a significant increase in the prevalence of diabetes over the last few years, particularly in India. It is a highly prevalent group of metabolic diseases associated with long term damage, dysfunction and failure of various organs especially the eyes. As majority of all diabetic patients have Type- II diabetes or adult onset diabetes [10], this study has been directed towards those patients. Thus the present study was carried out to evaluate the impact of diabetes mellitus on anterior chamber width in relation to duration of disease and severity of retinopathy which has been analyzed with a proper statistical tool.

We carried out a cross-sectional study in 125 patients (250 eyes) who presented to our hospital who had type II diabetes mellitus. A thorough history and complete ophthalmologic examination was done which includes best corrected visual acuity, intra-ocular pressure measurement, gonioscopy to view the angle of anterior chamber, detailed anterior segment examination and dilated fundus examination. Studies have shown that diabeticshave shallow anterior chamber and thicker lens than non diabetics. Diabetic patients who have shallow anterior chambers are prone for angle closure glaucoma. This study has found significant statisticalcorrelation between the width of anterior chamber angle and duration of diabetes mellitus. There was also a statistically significant correlation between the width of anterior chamber angle and the severity of diabetic retinopathy.

Since shallow anterior chamber can be a predisposing factor for developing angle closure glaucoma, gonioscopy can be used as a screening tool for diabetic patients particularly in those with a longer duration of the disease and as severity of retinopathy progresses.

Funding: Nil, Conflict of interest: Nil Permission from IRB: Yes

\section{References}

1. Mitchell P, Smith W, Chey T, et al. Open-angle glaucoma and diabetes: the Blue Mountains eye study, Australia. Ophthalmology. 1997 Apr;104(4):712-8.

2. Saw SM, Wong TY, Ting S, et al. The relationship between anterior chamber depth and the presence of diabetes in the Tanjong Pagar Survey. Am J Ophthalmol. 2007Aug;144(2):325-6.DOI:10.1016/j.ajo. 2007. 03.038

3. Standards of Medical Care in Diabetes. Diabetes Care 2010: 33 (1):11-61.

4. American Diabetes Association. Diagnosis and classification of diabetes mellitus. Diabetes Care. 2008 Jan; 31 Suppl 1:S55-60. doi: 10.2337/dc08-S055.

5. Løgstrup N, Sjølie AK, Kyvik KO, et al. Long-term influence of insulin dependent diabetes mellitus on refraction and its components: a population based twin study. Br J Ophthalmol. 1997 May;81(5):343-9.

6. Tai MC, Lin SY, Chen JT, et al. Sweet hyperopia: refractive changes in acute hyperglycemia. Eur $\mathrm{J}$ Ophthalmol. 2006 Sep-Oct;16(5):663-6.

7. Williams DL. Lens morphometry determined by Bmode ultrasonography of the normal and cataractous canine lens. Vet Ophthalmol. 2004 Mar-Apr;7(2):91-5.

8. Devereux JG, Foster PJ, Baasanhu J, et al. Anterior chamber depth measurement as a screening tool for primary angle-closure glaucoma in an East Asian population. Arch Ophthalmol. 2000 Feb;118(2):257-63.

9. Foster PJ, Devereux JG, Alsbirk PH, et al. Detection of gonioscopically occludable angles and primary angle closure glaucoma by estimation of limbal chamber depth in Asians: modified grading scheme. $\mathrm{Br} \mathrm{J}$ Ophthalmol. 2000 Feb; 84 (2): 186-92.

10. Diagnosis and classification of diabetes mellitus. Diabetes Care 2008; 3(1): 45-9.

\section{How to cite this article?}

Khanna N. S, Anitha J. Study of angle of anterior chamber in patients with Type 2 Diabetes Mellitus. Trop J Ophthalmol Otolaryngol.2019;4(1):38-41.doi:10.17511/jooo.2019.i01.08 